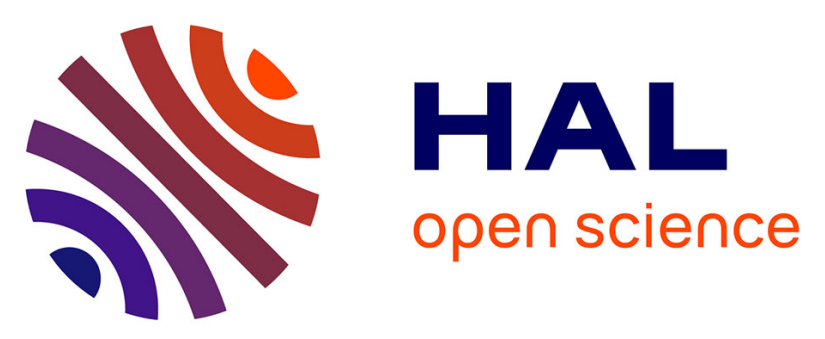

\title{
Cellular accumulation of fluoroquinolones is not predictive of their intracellular activity: studies with gemifloxacin, moxifloxacin and ciprofloxacin in a pharmacokinetic/pharmacodynamic model of uninfected and infected macrophages
}

Coralie M. Vallet, Béatrice Marquez, Eva Ngabirano, Sandrine Lemaire, Marie-Paule Mingeot-Leclercq, Paul M. Tulkens, Françoise van Bambeke

\section{- To cite this version:}

Coralie M. Vallet, Béatrice Marquez, Eva Ngabirano, Sandrine Lemaire, Marie-Paule MingeotLeclercq, et al.. Cellular accumulation of fluoroquinolones is not predictive of their intracellular activity: studies with gemifloxacin, moxifloxacin and ciprofloxacin in a pharmacokinetic/pharmacodynamic model of uninfected and infected macrophages. International Journal of Antimicrobial Agents, 2011, 10.1016/j.ijantimicag.2011.05.011 . hal-00722865

\section{HAL Id: hal-00722865 \\ https://hal.science/hal-00722865}

Submitted on 6 Aug 2012

HAL is a multi-disciplinary open access archive for the deposit and dissemination of scientific research documents, whether they are published or not. The documents may come from teaching and research institutions in France or abroad, or from public or private research centers.
L'archive ouverte pluridisciplinaire HAL, est destinée au dépôt et à la diffusion de documents scientifiques de niveau recherche, publiés ou non, émanant des établissements d'enseignement et de recherche français ou étrangers, des laboratoires publics ou privés. 


\section{Accepted Manuscript}

Title: Cellular accumulation of fluoroquinolones is not predictive of their intracellular activity: studies with gemifloxacin, moxifloxacin and ciprofloxacin in a pharmacokinetic/pharmacodynamic model of uninfected and infected macrophages

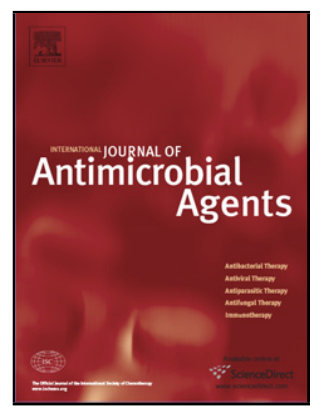

Authors: Coralie M. Vallet, Béatrice Marquez, Eva Ngabirano, Sandrine Lemaire, Marie-Paule Mingeot-Leclercq, Paul M.

Tulkens, Françoise Van Bambeke

PII:

DOI:

Reference:

To appear in:

Received date:

Revised date:

Accepted date:
S0924-8579(11)00252-4

doi:10.1016/j.jjantimicag.2011.05.011

ANTAGE 3636

International

Journal

of

Antimicrobial

Agents

Please cite this article as: Vallet CM, Marquez B, Ngabirano E, Lemaire S, MingeotLeclercq M-P, Tulkens PM, Van Bambeke F, Cellular accumulation of fluoroquinolones is not predictive of their intracellular activity: studies with gemifloxacin, moxifloxacin and ciprofloxacin in a pharmacokinetic/pharmacodynamic model of uninfected and infected macrophages, International Journal of Antimicrobial Agents (2010), doi:10.1016/j.ijantimicag.2011.05.011

This is a PDF file of an unedited manuscript that has been accepted for publication. As a service to our customers we are providing this early version of the manuscript. The manuscript will undergo copyediting, typesetting, and review of the resulting proof before it is published in its final form. Please note that during the production process errors may be discovered which could affect the content, and all legal disclaimers that apply to the journal pertain. 
1 Cellular accumulation of fluoroquinolones is not predictive of their

2 intracellular activity: studies with gemifloxacin, moxifloxacin, and

3

4

5

6

8

9 ciprofloxacin in a pharmacokinetic/pharmacodynamic model of uninfected and infected macrophages.

Coralie M. Vallet, Béatrice Marquez, ${ }^{\$}$ Eva Ngabirano, Sandrine Lemaire, Marie-Paule Mingeot-Leclercq, Paul M. Tulkens*, and Françoise Van Bambeke

Pharmacologie cellulaire et moléculaire, Louvain Drug Research Institute, Université catholique de Louvain, Brussels, Belgium

Running title: Cellular pharmacokinetics and activity of fluoroquinolones

\$Present address: Grupo Tumorigenesis endocrina y regulación hormonal del cáncer, Instituto de Biomedicina de Sevilla - Hospitales Universitarios Virgen del Rocío, Avenida Manuel Siurot s/n, 41013 Sevilla, Spain.

\section{${ }^{*}$ Corresponding author}

Pharmacologie cellulaire et moléculaire,

Université catholique de Louvain,

Avenue E. Mounier 73 bte B1.73.05,

B-1200 Bruxelles, Belgium.

Phone: +32-2-764-73-71.

Fax: $+32-2-764-73-73$

E-mail: tulkens@facm.ucl.ac.be 


\section{ABSTRACT}

31 Fluoroquinolones enter eukaryotic cells but the correlation between cellular accumulation and activity remains poorly established. Gemifloxacin is known to accumulate to a larger extent than most other fluoroquinolones in tissues. Using murine J774 macrophages and human THP-1 monocytes, we show that gemifloxacin accumulates more than ciprofloxacin and even moxifloxacin. While showing indistinguishable kinetics of accumulation in J774 macrophages, gemifloxacin was released at an approximately two-fold slower rate than ciprofloxacin and its release was only partial. Gemifloxacin was also a weaker substrate than ciprofloxacin for the efflux transporter Mrp4 active in J774 macrophages. In cells infected with L. monocytogenes or S. aureus (typical cytoplasmic and phagolysosomal organisms, respectively), gemifloxacin was equipotent to moxifloxacin and ciprofloxacin in concentration-dependent experiments if data are normalized based on MIC in broth. Thus, larger cellular concentrations of gemifloxacin than of moxifloxacin or ciprofloxacin were needed to obtain a similar target effect. Fractionation studies showed a similar subcellular distribution for all 3 fluoroquinolones, with about $2 / 3$ of the cell-associated drug recovered in the soluble fraction (cytosol). The data suggest that the cellular accumulation of fluoroquinolones is largely a self-defeating process as far as activity is concerned, with the intracellular drug made inactive in proportion to its accumulation level. While these observations do not decrease the intrinsic value of fluoroquinolones for treatment of intracellular infections, they indicate that ranking fluoronolones based on cell accumulation data without measuring the corresponding intracellular activity may lead to incorrect conclusions concerning their real potential. monocytogenes, macrophages 

respectively.

\section{Introduction}

Fluoroquinolone antibiotics are important in our current therapeutic arsenal, because of their broad spectrum, highly bactericidal activity, and favourable pharmacokinetic properties [1]. Their wide tissue distribution allows them reaching therapeutic concentrations in deep body compartments as well as in the intracellular milieu, which may be an advantage in the treatment of intracellular infections. Accumulation and activity in cells are usually linked when considering a given fluoroquinolone in a specific cell type, as demonstrated for ciprofloxacin vis-à-vis the intracellular forms of L. monocytogenes in J774 macrophages in experiments where its cellular concentration was modulated by inhibition or overexpression of the constitutive ciprofloxacin efflux transporter Mrp4 [2;3]. There is, however, a lack of quantitative data comparing distinct fluoroquinolones in this context.

Gemifloxacin [4] accumulates to high levels in human PMN and is active against intracellular bacteria $[5 ; 6]$. This prompted us to compare it to other fluoroquinolones for cellular pharmacokinetics and activity in an established model of murine J774 macrophages [7]. Ciprofloxacin and moxifloxacin, when needed, were used comparators, as these show a low and large accumulation, respectively, in relation to differential susceptibility to efflux [8-11]. We also examined THP-1 cells, where no active fluoroquinolone efflux has been evidenced so far. We found that gemifloxacin accumulates to higher levels than ciprofloxacin and moxifloxacin in both cell types and that all three drugs have a similar subcellular distribution. Yet, gemifloxacin showed no improved activity against two types of intracellular bacteria, L. monocytogenes and S. aureus, localized in the cytosol and in phagolysosomes, 


\section{Materials and methods}

\subsection{Antibiotics and main reagents}

Gemifloxacin mesylate (LG Life Sciences, Seoul, Korea), and ciprofloxacin-HCl and moxifloxacin-HCl (Bayer HealthCare AG, Leverkusen, Germany) were obtained as microbiological standards (potencies: $79 \%, 85 \%$, and $91 \%$ ). Gemfibrozil was from SigmaAldrich (St-Louis, MO, USA), human serum from Lonza Ltd (Basel, Switzerland), and cell culture media and sera from Invitrogen Corp. (Carlsbad, CA).

\subsection{Cell lines}

Murine $\mathbf{J 7 7 4}$ macrophages (wild-type cells [9]) and their ciprofloxacin-resistant derivatives overexpressing Mrp4 efflux transporter [8;11] were used for most experiments. Human THP1 cells (ATCC TIB-202, American Tissue Culture Collection, Manassas, VA) [12;13] were used for comparison purposes. ATP depletion was obtained as previously described [9].

\subsection{Determination of the cellular accumulation of fluoroquinolones.}

We used a previously described protocol $[9 ; 14]$. Cell -associated fluoroquinolones were assayed by fluorimetry (see [10] for ciprofloxacin and moxifloxacin; for gemifloxacin, the conditions were: $\lambda_{\text {ex. }}=270 \mathrm{~nm} ; \lambda_{\text {em }}=402 \mathrm{~nm}$ [lowest limit of detection: $50 \mu \mathrm{g} / \mathrm{L}$; linearity: 0 $1.5 \mathrm{mg} / \mathrm{L}])$. The cell drug content was expressed by reference to the total cell protein content [15]. The apparent total cellular concentration was then calculated using a conversion factor of $3.08 \mu \mathrm{L}$ of cell volume per mg of cell protein [9].

\subsection{Cell fractionation studies in $\mathbf{J 7 7 4}$ cells}

The main subcellular organelles were separated by differential centrifugation as previously described [2]. The protein and antibiotic content of each fraction was determined in parallel with the activity of marker enzymes of the main organelles (cytochrome c-oxydase for mitochondria; $\mathrm{N}$-acetyl- $\beta$-hexosaminidase for lysosomes, and lactate dehydrogenase for cytosol [7]). 


\subsection{Bacterial strains and susceptibility testings.}

110

111

112

113

114

115

116

117

118

119

120

121

122

123

124

125

126

127

128

129

We used L. monocytogenes strain EGD and S. aureus strain ATCC 25923. MIC determinations were made according to CLSI guidelines [16], using Tryptic Soy broth for $L$. monocytogenes [13] and Mueller Hinton broth for S. aureus [14].

\subsection{Cell infection and assessment of antibiotic intracellular activities.}

Cell infection was performed as described previously [2], with pharmacological comparison between drugs and bacteria based on concentration-dependent effects analyses [14], to determine (i) the relative minimal and maximal efficacies $\left(E_{\min } / E_{\max }\right.$, in $\log _{10}$ units), and (ii) the relative potencies $\left(\mathrm{EC}_{50}\right)$ and static concentrations). This type of analysis and its usefulness for comparing antibiotics and the response of different bacteria has been described in details in previous publications [14;17-19]). As discussed previously [20], the large dilution of samples before spreading on agar plates for cfu counting ensures an absence of carry-over effect.

\subsection{Curve fitting and statistical analyses}

Curve-fitting analyses were made using GraphPad Prism® version 4.03, GraphPad Software, San Diego, CA, USA. Statistical analyses were made with the same software for comparing concentration-response functions and with GraphPad Instat® version 3.06 (GraphPad Software) for other studies. 


\section{Results}

131

132

133

134

135

136

137

138

139

140

141

142

143

144

145

146

147

148

149

150

151

152

153

\subsection{Cellular pharmacokinetics}

We first compared the cellular accumulation of gemifloxacin with that of ciprofloxacin and moxifloxacin, and examined the influence of gemfibrozil, a broad spectrum inhibitor of anion transporters including the Mrp transporters, on this accumulation. Figure $1 \mathrm{~A}$ (upper panels) shows that (i) gemifloxacin accumulated to a larger extent than the other two fluoroquinolones in both $\mathrm{J774}$ and THP-1 cells; (ii) the accumulation of gemifloxacin and moxifloxacin was not influenced by gemfibrozil; (iii) in contrast, ciprofloxacin, which accumulated to the lowest extent in $\mathbf{J 7 7 4}$ macrophages, reached a cellular concentration similar to that of moxifloxacin in these cells in the presence of gemfibrozil, as already observed in the same model [10]; (iv) the level of accumulation of ciprofloxacin was similar to that of moxifloxacin in THP-1 cells and not influenced by the addition of gemfibrozil.

We then compared the kinetics of accumulation and efflux of gemifloxacin with that of ciprofloxacin using $\mathbf{J 7 7 4}$ macrophages only as this is where the largest difference of accumulation was observed. Figure $1 \mathrm{~B}$ shows that the two fluoroquinolones could not be distinguished with respect to accumulation kinetics but displayed marked differences for efflux. Thus, gemifloxacin release (i) occurred at the same rate as its uptake (compare $k_{\text {in }}$ and $k_{\text {out }}$ parameters); (ii) was about 2-fold slower than that of ciprofloxacin, including at the very initial period phase (see inset); (iii) was only partial, with about $25 \%$ of the accumulated drug remaining cell-associated in apparent stable fashion after $30 \mathrm{~min}$ incubation in drug-free medium vs. negligible amounts for ciprofloxacin.

\section{We next measured the level of accumulation of gemifloxacin compared to that of} ciprofloxacin in J774 macrophages overexpressing the ciprofloxacin efflux transporter Mrp4 (ciprofloxacin-resistant cells), using normal conditions and conditions of ATP depletion (which inhibits all ATP-dependent active transporters including Mrp4). Figure 2A (upper 
157

158

159

160

161

162

163

164

165

166

167

168

169

170

171

172

173

174

175

176

177

178

179

180

181

182

183

panels) shows that (i) gemifloxacin accumulation was reduced (but in a non-statistically

significant manner) in ciprofloxacin-resistant cells compared to wild-type cells; (ii) ATP depletion increased its accumulation in both wild-type and ciprofloxacin-resistant cells, but with a significant difference in the latter cells only; (iii) ciprofloxacin accumulation was significantly reduced in ciprofloxacin-resistant cells, but was markedly increased by ATP depletion, reaching a value similar to that observed in wild-type cells after ATP depletion; (iv) in line with our previous observations [11], ATP depletion markedly increased the accumulation of ciprofloxacin in wild-type cells.

Because the ciprofloxacin efflux transporter is saturable in a $10-200 \mathrm{mg} / \mathrm{L}$ range [9], we measured the accumulation of gemifloxacin in both wild-type $\mathrm{J} 774$ macrophages and ciprofloxacin-resistant cells over increasing concentrations of gemifloxacin in that range.

Figure 2 (lower panel) shows that while gemifloxacin accumulation was not significantly influenced by its extracellular concentration in wild-type cells, there was a significant increase over the range of concentrations investigated for ciprofloxacin-resistant cells. In contrast, and as described earlier [9], ciprofloxacin showed a marked increase in its accumulation over the same concentration range in wild-type cells. For ciprofloxacin-resistant cells, the increase in cell accumulation of ciprofloxacin was much less marked in the range of drug concentrations investigated due to overexpression of the Mrp4 transporter (see [11]).

These results suggest that gemifloxacin could be a poor, albeit still recognized substrate for efflux transport in $\mathrm{J} 774$ macrophages if Mrp4 is overexpressed. We, therefore, compared the kinetics of gemifloxacin efflux in ciprofloxacin-resistant vs. wild-type cells. While the plateau values observed at 30 min remained close from each other, denoting an incomplete release of gemifloxacin in both cases, its rate of efflux was significantly accelerated in ciprofloxacinresistant cells compared to wild-type cells $\left(k_{\text {out }}=2.393 \pm 0.907\right.$ vs. $0.403 \pm 0.122 \mathrm{~min}^{-1}$; $p<0.001$; see graphical representation in Figure SP1 in the Supplementary Material). 


\subsection{Intracellular activity}

185

186

187

188

189

190

191

192

193

194

195

196

197

198

199

200

201

202

203

204

205

206

207

208

209

210

To examine the correlation between cellular accumulation and intracellular activity, we compared all 3 fluoroquinolones in our pharmacological model of intracellular infection [14;17], using $\mathrm{J} 774$ macrophages since this is where the largest differences in accumulation levels had been observed. L. monocytogenes and S. aureus were selected as bacterial targets as they represent a typical cytoplasmic and phagolysosomal organism, respectively. Data presented in Figure 3A (with analysis of the key pharmacological descriptors in Table 1) show that all 3 antibiotics induced essentially a similar response when expressed as a function of equipotent extracellular concentrations (multiples of MIC). Thus, in all cases, a single sigmoid function could be fitted to the individual responses of each antibiotic (see Figure SP2 in the Supplementary Material and the pertinent regression parameters and pharmacological descriptors in Table 1). As no statistically significant difference was observed between the 3 antibiotics, all data were pooled to fit a single function shown in Figure 3A. Thus, for each bacterium, the relative minimal efficacies $\left(E_{\min }\right.$ [growth in the absence of antibiotic]), maximal relative efficacies ( $E_{\max }$ [maximal antibiotic-related killing]), relative potencies $\left(E_{50}\right)$, and static concentrations $\left(C_{s}\right.$; [in multiples of MIC) were not statistically significantly different. We then calculated for each fluoroquinolone which cellular drug concentration would be needed to reach two predefined pharmacodynamic targets (static effect and a 1 or $2 \log _{10}$ cfu decrease). The results (with the mode of calculation) are presented in Figure 3B and show that the potencies of the drugs with respect to their intracellular targets is in inverse proportion to their respective cellular accumulations.

\subsection{Subcellular distribution}

Lastly, we compared the subcellular distributions of ciprofloxacin, moxifloxacin, and gemifloxacin. Figure 4 shows that all 3 fluoroquinolones shared essentially the same distribution, with about $70 \%$ recovered in the soluble fraction, about $10 \%$ of ciprofloxacin and gemifloxacin and $18 \%$ of moxifloxacin in the nuclei/unbroken cells fraction, and the 
211 remaining in the organelles/membranes fraction. As previously described [7], lactate

212 dehydrogenase was mostly recovered in the soluble fraction, and cytochrome oxydase and

$213 \mathrm{~N}$-acetyl- $\beta$-hexosaminidase, in the granules/membranes fraction, indicating that the

214 fractionation method effectively separated the corresponding subcellular entities with only a 215 very low proportion of unbroken cells left after homogenization.

216 


\section{4. Discussion}

218 Gemifloxacin, approved for clinical use in over 27 countries [21], is characterized by very low 219 MICs against Gram-positive bacteria [22;23] related to the presence of an oximinomethyl 220 group [4] in its C7 side-chain and by a high tissular accumulation [24]. Human PK/PD 221 studies show that gemifloxacin achieves higher AUC/MIC ratios in epithelial lining fluid and 222 alveolar macrophages than other currently used fluoroquinolones, suggesting an advantage 223 in terms of availability and efficacy at the site of infection [25;26]. The present study, 224 however, shows that the higher accumulation of gemifloxacin in J774 macrophages (i) is not associated with differences in influx rates compared to a fluoroquinolone with lower accumulation (ciprofloxacin); (ii) does not preclude and cannot be explained by differences in active efflux transport (in comparison with moxifloxacin); (iii) does not lead to a higher intracellular activity. This goes against commonly accepted pharmacokinetic and pharmacodynamic concepts that tend to link accumulation and lack of efflux on the one hand, and accumulation and activity on the other hand. Our model may be questioned, but it is important to note that it reproduces (i) with respect to pharmacokinetics, what is observed in human alveolar macrophages where the concentrations of ciprofloxacin, moxifloxacin, and gemifloxacin are respectively $2-5 \times, 20-40 \times$, and $90 \times$ higher than serum levels [26-28], and (ii) with respect to intracellular activity what has been observed in human polymorphonuclear leucocytes infected by $S$. aureus [5].

Mechanistically, differences in accumulation of drugs in cells and tissues usually result from commensurate differences in influx or efflux rates, or from differential trapping by intracellular organelles or constituents.

241 Considering influx first, faster drug accumulation is usually related to a higher lipophilicity

242 (which is supposed to facilitate transmembrane diffusion) or from the activity of transporters.

243 This does not seem to apply to gemifloxacin, as this fluoroquinolone (i) is not globally more 244 lipophilic than ciprofloxacin (see Table SP1 for experimental and calculated log P and $\log$ D 
245 values), (ii) is probably not the substrate of a specific influx transporter when compared to

246 ciprofloxacin (same rate accumulation constants). Non-specific influx transporter(s)

247 observed in PMN and human monocytes [29-31] can probably be dismissed here as these

248 belong to the Solute Carrier Organic Anion (SLCO) family [32] that is inhibited by gemfibrozil, 249 which was not the case here.

250

251 Considering efflux, Mrp4 has been proposed as the main transporter responsible for the

252 lower accumulation of ciprofloxacin in $\mathbf{J 7 7 4}$ macrophages compared to levofloxacin,

253 garenoxacin, and moxifloxacin. These fluoroquinolones, indeed, reach a similar level of

254 accumulation when Mrp4 is made inactive by ATP depletion or addition of gemfibrozil [10].

255 Moreover, ciprofloxacin accumulation is significantly increased by silencing the gene coding

256 for Mrp4 [8]. The present data show that this conclusion cannot be generalized to all

257 fluoroquinolones and all situations. Thus gemifloxacin not only accumulates more than

258 moxifloxacin in J774 macrophages under conditions of ATP depletion or in the presence of

259 gemfibrozil, but also in THP-1 macrophages in which no gemfibrozil-inhibited efflux can be

260 demonstrated. Another compelling reason to disregard efflux as being the main cause for

261 the differential accumulation of gemifloxacin vs. ciprofloxacin and moxifloxacin is that

262 gemifloxacin actually seems a weak but nevertheless effective substrate of Mrp4 in J774

263 macrophages, whereas we know that moxifloxacin is not. Thus, globally and in contrast to

264 what we proposed for moxifloxacin, the higher cellular concentration of gemifloxacin

265 compared to other fluoroquinolones must find an explanation beyond considerations of influx

266 and efflux rates only.

267

268 Considering intracellular trapping, a model has been presented [33] that relates

269 fluoroquinolone accumulation in eukaryotic cells to their trapping under a protonated form in

270 lysosomes due to the acid $\mathrm{pH}(\sim 5.4)$ prevailing therein. This, however, is unlikely because

271 fluoroquinolones are not weak bases but zwitterionic compounds. Moreover, differences in

272 accumulation of drugs in acidic membrane-bounded compartments should result from 
273 commensurate differences in the number and/or the $\mathrm{pK}_{\mathrm{a}}$ of their basic functions (see [34]),

274 which is not the case for the 3 fluoroquinolones studied here (see individual basic $\mathrm{pK}_{\mathrm{a}}$ values

275 in Table SP1). More factually, cell fractionation studies show a predominant association of

276 the cell-associated fluoroquinolones with the cytosol rather than with lysosomes, in line with

277 the results of previous studies with ciprofloxacin [2;35] (studies using the same technique

278 have shown that macrolides are predominantly associated with lysosomes in $\mathrm{J774}$

279 macrophages [2;36;37]). Lastly, experimental studies have shown a lack of effect of

280 monensin $\left(\mathrm{a} \mathrm{H}^{+}\right.$ionophore that collapses the cytosolic-lysosomal $\left.\Delta \mathrm{pH}\right)$ on ciprofloxacin

281 accumulation under conditions in which it drastically reduces the accumulation of

282 azithromycin in $\mathrm{J774}$ macrophages [9].

283

284 Actually, a more likely explanation for the larger cellular accumulation of gemifloxacin

compared to moxifloxacin and ciprofloxacin could be its tighter binding to still undefined

cellular constituents such as soluble proteins. This hypothesis would account for the pharmacokinetic and subcellular distribution data presented here, including (i) the lower efflux rate of gemifloxacin compared to ciprofloxacin (which, however, may also result from the less efficient recognition of gemifloxacin by the Mrp4 efflux transporter, both mechanisms being not mutually exclusive) and, (ii) its incomplete release upon transfer of the cells to drug-free medium. It is also consistent with the larger serum protein binding of gemifloxacin (55-73 \%) compared to moxifloxacin (39-52\%) and ciprofloxacin (30 \% only) [38;39].

294 Determining the molecular nature of the intracellular binding sites for fluoroquinolones still require further investigations, but the mechanism proposed provides a rational explanation for the main critical observation made here, namely that all 3 fluoroquinolones are equipotent against intracellular bacteria in spite of their differences in cellular accumulation. We show, indeed, that it is the MIC of each drug that drives its intracellular potency (as defined by the

$299 \mathrm{C}_{\mathrm{s}}$ and $\mathrm{EC}_{50}$ pharmacological descriptors) since all 3 fluoroquinolones show superimposable 300 concentration-effects relationships once the data are normalized on basis of multiples of the 
MIC. MICs are measured in broth where little protein binding takes place, which means that

302 their values must essentially be interpreted as corresponding to free drug levels [40].

303 Intracellularly, a static effect $\left(\mathrm{C}_{\mathrm{s}}\right)$ for gemifloxacin was obtained for an extracellular

304 concentration corresponding to its MIC, although its intracellular concentration is much

305 larger. It is, therefore, tempting to speculate that only a fraction of the total intracellular

306 gemifloxacin is available for activity, corresponding essentially to its free form. Moxifloxacin

307 should show an intermediate behaviour with intracellular activity also driven by its MIC

308 (measured in broth), which is what we observe. Thus, the larger cellular accumulation of

309 some fluoroquinolones, taking gemifloxacin an example, would essentially be a self-defeating

310 process as far as activity is concerned (assuming all comparisons are made on basis of the

311 MIC), leading to a larger concentration of bound drugs with, however, no or little difference in

312 their free forms. This confirms and extends previous work that showed that the intracellular

313 activity of fluoroquinolones was weaker and not in proportion to what could be anticipated

314 from the level of their cellular accumulation [13;41-43].

316 In conclusion, the present work documents that (i) recording the cellular accumulation of

317 fluoroquinolones does not allow to predict their intracellular activity; (ii) a higher cellular

318 accumulation may depend from other parameters than influx and efflux rates and/or the

319 activity of specific transporters. This calls for both more mechanistic studies and more

320 comprehensive structure-activity analyses where these two important elements of the

321 pharmacological properties of fluoroquinolones will be examined in a systematic fashion. 


\section{Acknowledgments}

323 We are grateful to M.C. Cambier, C. Misson, and M. Vergauwen for dedicated technical

324 assistance. We thank the Oscient Pharmaceuticals Corporation and Bayer HealthCare for 325 the kind gift of gemifloxacin, and of moxifloxacin and ciprofloxacin, respectively.

\section{Declarations}

328 Funding: C.M.V. is Boursier of the Belgian Fonds pour la Recherche dans I'Industrie et 329 I'Agriculture (F.R.I.A.), B.M. was post-doctoral fellow of the First post-doc programme of the 330 Belgian Région wallonne, S.L. and F.V.B. are Chargé de Recherches and Maître de 331 Recherches of the Belgian Fonds de la Recherche Scientifique (F.R.S.-FNRS), respectively. 332 This work was supported by the Belgian Fonds de la Recherche Scientifique Médicale 333 (grants no. 3.4.597.06 and 3.4.583.08) and the Belgian Fonds de la Recherche Scientifique 334 (grant no. 1.5.195.07).

335 Competing interests: None

336 Ethical approval: Not applicable 


\section{References}

339 [1] Van Bambeke F, Michot JM, Van Eldere J, Tulkens PM. Quinolones in 2005: an update. Clin Microbiol Infect 2005; 11:256-280.

[2] Seral C, Carryn S, Tulkens PM, Van Bambeke F. Influence of P-glycoprotein and MRP efflux pump inhibitors on the intracellular activity of azithromycin and ciprofloxacin in macrophages infected by Listeria monocytogenes or Staphylococcus aureus. $J$ Antimicrob Chemother 2003; 51:1167-1173.

[3] Lismond A, Tulkens PM, Mingeot-Leclercq MP, Courvalin P, Van Bambeke F. Cooperation between prokaryotic (Lde) and eukaryotic (MRP) efflux transporters in J774 macrophages infected with Listeria monocytogenes: studies with ciprofloxacin and moxifloxacin. Antimicrob Agents Chemother 2008; 52:3040-3046.

[4] Hong CY, Kim YK, Chang JH, Kim SH, Choi H, Nam DH et al. Novel fluoroquinolone antibacterial agents containing oxime-substituted (aminomethyl)pyrrolidines: synthesis and antibacterial activity of 7-(4-(aminomethyl)-3-(methoxyimino)pyrrolidin-1-yl)-1cyclopropyl-6- fluoro-4-oxo-1,4-dihydro[1,8]naphthyridine-3-carboxylic acid (LB20304). J Med Chem 1997; 40:3584-3593.

[5] Garcia I, Pascual A, Ballesta S, Joyanes P, Perea EJ. Intracellular penetration and activity of gemifloxacin in human polymorphonuclear leukocytes. Antimicrob Agents Chemother 2000; 44:3193-3195.

[6] Baltch AL, Bopp LH, Smith RP, Michelsen PB, Ritz WJ. Antibacterial activities of gemifloxacin, levofloxacin, gatifloxacin, moxifloxacin and erythromycin against intracellular Legionella pneumophila and Legionella micdadei in human monocytes. J Antimicrob Chemother 2005; 56:104-109. 
[7] Renard C, Vanderhaeghe HJ, Claes PJ, Zenebergh A, Tulkens PM. Influence of conversion of penicillin $\mathrm{G}$ into a basic derivative on its accumulation and subcellular localization in cultured macrophages. Antimicrob Agents Chemother 1987; 31:410-416.

364

365

366

367

368

369

370

371

372

373

374

375

376

377

378

379

380

381

382

383

384

[8] Marquez B, Caceres NE, Mingeot-Leclercq MP, Tulkens PM, Van Bambeke F. Identification of the efflux transporter of the fluoroquinolone antibiotic ciprofloxacin in murine macrophages: studies with ciprofloxacin-resistant cells. Antimicrob Agents Chemother 2009; 53:2410-2416.

[9] Michot JM, Van Bambeke F, Mingeot-Leclercq MP, Tulkens PM. Active efflux of ciprofloxacin from J774 macrophages through an MRP-like transporter. Antimicrob Agents Chemother 2004; 48:2673-2682.

[10] Michot JM, Seral C, Van Bambeke F, Mingeot-Leclercq MP, Tulkens PM. Influence of efflux transporters on the accumulation and efflux of four quinolones (ciprofloxacin, levofloxacin, garenoxacin, and moxifloxacin) in $\mathrm{J} 774$ macrophages. Antimicrob Agents Chemother 2005; 49:2429-2437.

[11] Michot JM, Heremans MF, Caceres NE, Mingeot-Leclercq MP, Tulkens PM, Van Bambeke F. Cellular accumulation and activity of quinolones in ciprofloxacin-resistant J774 macrophages. Antimicrob Agents Chemother 2006; 50:1689-1695.

[12] Tsuchiya S, Yamabe M, Yamaguchi Y, Kobayashi Y, Konno T, Tada K. Establishment and characterization of a human acute monocytic leukemia cell line (THP-1). Int J Cancer 1980; 26:171-176.

[13] Carryn S, Van Bambeke F, Mingeot-Leclercq MP, Tulkens PM. Comparative intracellular (THP-1 macrophage) and extracellular activities of beta-lactams, azithromycin, gentamicin, and fluoroquinolones against Listeria monocytogenes at clinically relevant concentrations. Antimicrob Agents Chemother 2002; 46:2095-2103. 
[14] Barcia-Macay M, Seral C, Mingeot-Leclercq MP, Tulkens PM, Van Bambeke F. Pharmacodynamic evaluation of the intracellular activities of antibiotics against Staphylococcus aureus in a model of THP-1 macrophages. Antimicrob Agents Chemother 2006; 50:841-851.

[15] Lowry OH, N.J.Rosebrough, A.L.Farr, R.J.Randall. Protein measurement with the Folin phenol reagent. J Biol Chem 1951; 193:265-275.

[16] Anonymous. Methods for dilution antimicrobial susceptibility tests for bacteria that grow aerobically - Approved standard. Clinical and Laboratory Standard Institute, Wayne, PA, 2010.

[17] Lemaire S, Van Bambeke F, Mingeot-Leclercq MP, Tulkens PM. Activity of three \{beta\}lactams (ertapenem, meropenem and ampicillin) against intraphagocytic Listeria monocytogenes and Staphylococcus aureus. J Antimicrob Chemother 2005; 55:897904.

[18] Lemaire S, Van Bambeke F, Mingeot-Leclercq MP, Glupczynski Y, Tulkens PM. Role of acidic $\mathrm{pH}$ in the susceptibility of intraphagocytic methicillin-resistant Staphylococcus aureus strains to meropenem and cloxacillin. Antimicrob Agents Chemother 2007; $51: 1627-1632$.

[19] Lemaire S, Kosowska-Shick K, Appelbaum PC, Glupczynski Y, Van Bambeke F, Tulkens PM. Activity of moxifloxacin against intracellular community-acquired methicillin-resistant Staphylococcus aureus: comparison with clindamycin, linezolid and co-trimoxazole and attempt at defining an intracellular susceptibility breakpoint. J Antimicrob Chemother 2011; 66:596-607.

[20] Nguyen HA, Denis O, Vergison A, Theunis A, Tulkens PM, Struelens MJ et al. Intracellular activity of antibiotics in a model of human THP-1 macrophages infected by a Staphylococcus aureus small-colony variant strain isolated from a cystic fibrosis 
patient: pharmacodynamic evaluation and comparison with isogenic normal-phenotype and revertant strains. Antimicrob Agents Chemother 2009; 53:1434-1442.

412

[21] LG Life Sciences. LG Life Sciences 2009 Annual Report. 2010. Seoul, Korea, p. 18.

413

414

415

416

417

418

419

420

421

422

423

424

425

426

427

428

429

430

431

[22] Cormican MG, Jones RN. Antimicrobial activity and spectrum of LB20304, a novel fluoronaphthyridone. Antimicrob Agents Chemother 1997; 41:204-211.

[23] Oh Jl, Paek KS, Ahn MJ, Kim MY, Hong CY, Kim IC et al. In vitro and in vivo evaluations of LB20304, a new fluoronaphthyridone. Antimicrob Agents Chemother 1996; 40:1564-1568.

[24] Roy B, Das A, Bhaumik U, Sarkar AK, Bose A, Mukharjee J et al. Determination of gemifloxacin in different tissues of rat after oral dosing of gemifloxacin mesylate by LCMS/MS and its application in drug tissue distribution study. J Pharm Biomed Anal 2010; 52:216-226.

[25] Saravolatz LD, Leggett J. Gatifloxacin, gemifloxacin, and moxifloxacin: the role of 3 newer fluoroquinolones. Clin Infect Dis 2003; 37:1210-1215.

[26] Mandell LA, lannini PB, Tillotson GS. Respiratory fluoroquinolones: differences in the details. Clin Infect Dis 2004; 38:1331-1332.

[27] Capitano B, Mattoes HM, Shore E, O'Brien A, Braman S, Sutherland C et al. Steadystate intrapulmonary concentrations of moxifloxacin, levofloxacin, and azithromycin in older adults. Chest 2004; 125:965-973.

[28] Schuler P, Zemper K, Borner K, Koeppe P, Schaberg T, Lode H. Penetration of sparfloxacin and ciprofloxacin into alveolar macrophages, epithelial lining fluid, and polymorphonuclear leucocytes. Eur Respir J 1997; 10:1130-1136. 
432 [29] Hara T, Takemura H, Kanemitsu K, Yamamoto H, Shimada J. Comparative uptake of

433

434

435

436

437

438

439

440

441

442

443

444

445

446

447

448

449

450

451

452

453 grepafloxacin and ciprofloxacin by a human monocytic cell line, THP-1. J Infect Chemother 2000; 6:162-167.

[30] Bounds SJ, Nakkula R, Walters JD. Fluoroquinolone transport by human monocytes: characterization and comparison to other cells of myeloid lineage. Antimicrob Agents Chemother 2000; 44:2609-2614.

[31] Memin E, Panteix G, Revol A. Carrier-mediated system for pefloxacin uptake in human monocytes. J Antimicrob Chemother 1997; 40:263-268.

[32] Skazik C, Heise R, Bostanci O, Paul N, Denecke B, Joussen S et al. Differential expression of influx and efflux transport proteins in human antigen presenting cells. Exp Dermatol 2008; 17:739-747.

[33] Fresta M, Guccione S, Beccari AR, Furneri PM, Puglisi G. Combining molecular modeling with experimental methodologies: mechanism of membrane permeation and accumulation of ofloxacin. Bioorg Med Chem 2002; 10:3871-3889.

[34] de Duve C, de Barsy T, Poole B, Trouet A, Tulkens P, Van Hoof F. Commentary. Lysosomotropic agents. Biochem Pharmacol 1974; 23:2495-2531.

[35] Carlier MB, Scorneaux B, Zenebergh A, Desnottes JF, Tulkens PM. Cellular uptake, localization and activity of fluoroquinolones in uninfected and infected macrophages. $\mathrm{J}$ Antimicrob Chemother 1990; 26 Suppl B:27-39.

[36] Carlier MB, Zenebergh A, Tulkens PM. Cellular uptake and subcellular distribution of roxithromycin and erythromycin in phagocytic cells. J Antimicrob Chemother 1987; 20 Suppl B:47-56. 
454

455

456

457

458

459

460

461

462

463

464

465

466

467

468

469

470

471

472

473

474

475

476

477

[37] Carlier MB, Garcia-Luque I, Montenez JP, Tulkens PM, Piret J. Accumulation, release and subcellular localization of azithromycin in phagocytic and non-phagocytic cells in culture. Int J Tissue React 1994; 16:211-220.

[38] Lode H, Hoffken G, Boeckk M, Deppermann N, Borner K, Koeppe P. Quinolone pharmacokinetics and metabolism. J Antimicrob Chemother 1990; 26 Suppl B:41-49.

[39] Dudley MN. Pharmacokinetics of fluoroquinolones. In: Hooper DC, Wolfson JS, editors. Quinolone Antimicrobial Agents. Washington, DC: ASM Press, 2003: 115-132.

[40] Schmidt S, Rock K, Sahre M, Burkhardt O, Brunner M, Lobmeyer MT et al. Effect of protein binding on the pharmacological activity of highly bound antibiotics. Antimicrob Agents Chemother 2008; 52:3994-4000.

[41] Paillard D, Grellet J, Dubois V, Saux MC, Quentin C. Discrepancy between uptake and intracellular activity of moxifloxacin in a Staphylococcus aureus-human THP-1 monocytic cell model. Antimicrob Agents Chemother 2002; 46:288-293.

[42] Seral C, Barcia-Macay M, Mingeot-Leclercq MP, Tulkens PM, Van Bambeke F. Comparative activity of quinolones (ciprofloxacin, levofloxacin, moxifloxacin and garenoxacin) against extracellular and intracellular infection by Listeria monocytogenes and Staphylococcus aureus in J774 macrophages. J Antimicrob Chemother 2005; $55: 511-517$.

[43] Van de Velde S, Nguyen HA, Van Bambeke F, Tulkens PM, Grellet J, Dubois V et al. Contrasting effects of human THP-1 cell differentiation on levofloxacin and moxifloxacin intracellular accumulation and activity against Staphylococcus aureus and Listeria monocytogenes. J Antimicrob Chemother 2008; 62:518-521. 
Table 1: Pertinent regression parameters ${ }^{a}$ (with confidence intervals $[\mathrm{CI}]$ ) and statistical analyses of data from experiments examining the concentration-response activities of ciprofloxacin, moxifloxacin and gemifloxacin (shown in Figure 3A). The 3 first rows show the analysis for each individual antibiotic and the last row the analysis made for all pooled data.

\section{L. monocytogenes}

\begin{tabular}{|c|c|c|c|c|c|c|c|c|c|c|}
\hline \multirow{2}{*}{ antibiotic } & & \multirow{2}{*}{\multicolumn{2}{|c|}{$\begin{array}{c}\mathbf{E}_{\min }{ }^{b} \\
(\mathrm{Cl})\end{array}$}} & \multirow[b]{2}{*}{$\begin{array}{c}\mathbf{E}_{\max }{ }^{\mathbf{c}} \\
(\mathrm{Cl})\end{array}$} & \multirow[b]{2}{*}{$\begin{array}{c}\mathbf{E C}_{50}{ }^{\mathbf{d}} \\
(\mathrm{Cl})\end{array}$} & \multirow[b]{2}{*}{$\mathrm{C}_{\mathrm{s}}{ }^{\mathrm{e}}$} \\
\hline & $\mathbf{R}^{2}$ & $\begin{array}{c}\mathbf{E}_{\min }{ }^{\mathbf{b}} \\
(\mathrm{Cl})\end{array}$ & $\begin{array}{c}\mathbf{E}_{\max }{ }^{c} \\
(\mathrm{Cl})\end{array}$ & $\begin{array}{c}\mathbf{E C}_{50}{ }^{\mathrm{d}} \\
(\mathrm{Cl})\end{array}$ & $\mathrm{C}_{\mathrm{s}}{ }^{\mathrm{e}}$ & & & & & \\
\hline ciprofloxacin & 0.95 & $\begin{array}{c}2.82 \\
(1.83 \text { to } 3.81)\end{array}$ & $\begin{array}{c}-3.96 \\
(-5.44 \text { to }-2.48)\end{array}$ & $\begin{array}{c}2.94 \\
(1.00 \text { to } 8.66)\end{array}$ & 0.49 & 0.96 & $\begin{array}{c}3.80 \\
\text { (2.92 to } 4.68)\end{array}$ & $\begin{array}{c}-1.60 \\
(-2.26 \text { to }-0.94)\end{array}$ & $\begin{array}{c}1.36 \\
(0.64 \text { to } 2.89)\end{array}$ & 3.1 \\
\hline moxifloxacin & 0.95 & $\begin{array}{c}2.84 \\
(2.05 \text { to } 3.63)\end{array}$ & $\begin{array}{c}-4.48 \\
(-5.21 \text { to }-3.56)\end{array}$ & $\begin{array}{c}1.30 \\
(0.62 \text { to } 2.74)\end{array}$ & 0.47 & 0.95 & $\begin{array}{c}2.98 \\
(2.11 \text { to } 3.86)\end{array}$ & $\begin{array}{c}-1.85 \\
(-2.28 \text { to }-1.43)\end{array}$ & $\begin{array}{c}1.62 \\
(0.78 \text { to } 3.38)\end{array}$ & 2.6 \\
\hline gemifloxacin & 0.97 & $\begin{array}{c}3.03 \\
(1.79 \text { to } 4.27)\end{array}$ & $\begin{array}{c}-3.55 \\
(-4.28 \text { to }-2.82)\end{array}$ & $\begin{array}{c}0.65 \\
(0.27 \text { to } 1.59)\end{array}$ & 0.74 & 0.98 & $\begin{array}{c}3.07 \\
\text { (2.32 to } 3.83)\end{array}$ & $\begin{array}{c}-1.30 \\
(-1.64 \text { to }-0.97)\end{array}$ & $\begin{array}{c}2.02 \\
(1.01 \text { to } 4.03)\end{array}$ & 4.8 \\
\hline all 3 & 0.91 & $\begin{array}{c}3.44 \\
(2.95 \text { to } 3.94)\end{array}$ & $\begin{array}{c}-3.92 \\
(-4.53 \text { to }-3.32)\end{array}$ & $\begin{array}{c}1.44 \\
(0.95 \text { to } 2.19)\end{array}$ & 0.93 & 0.94 & $\begin{array}{c}3.44 \\
(2.95 \text { to } 3.94)\end{array}$ & $\begin{array}{c}-1.55 \\
(-1.81 \text { to }-1.29)\end{array}$ & $\begin{array}{c}1.44 \\
(0.95 \text { to } 2.19)\end{array}$ & 3.2 \\
\hline
\end{tabular}

481

${ }^{a}$ by use of all data for antibiotic concentrations ranging from approx. 0.01 to approx. 1,000 x MIC (ciprofloxacin: 0.01 to $100 \mathrm{mg} / \mathrm{L}$ [L. monocytogenes] and 0.001 to $100 \mathrm{mg} / \mathrm{L}$ [S. aureus]; moxifloxacin: 0.005 to $30 \mathrm{mg} / \mathrm{L}$ [L. monocytogenes] and 0.001 to $100 \mathrm{mg} / \mathrm{L}$ [S. aureus]; gemifloxacin: 0.005 to $150 \mathrm{mg} / \mathrm{L}$. [L. monocytogenes] and 0.0008 to $20 \mathrm{mg} / \mathrm{L}$ [S. aureus]).

${ }^{\mathbf{b}}$ relative minimal efficacy: change in cfu (in $\log _{10}$ units) at time $24 \mathrm{~h}$ from the initial, post-phagocytosis inoculum, as extrapolated for an infinitely low antibiotic concentration

c relative maximal efficacy: change in cfu (in $\log _{10}$ units) at time $24 \mathrm{~h}$ from the initial, post-phagocytosis inoculum, as extrapolated for an infinitely large antibiotic concentration 
$489{ }^{d}$ relative potency: extracellular concentration (in multiple of MIC) yielding a change in cfu at time $24 \mathrm{~h}$ half way between $\mathrm{E}_{\min }$ and $\mathrm{E}_{\max }$

490 e static concentration: concentration (in multiples of MIC) resulting no apparent bacterial growth (no change in cfu) from the initial, post-

491 phagocytosis inoculum), as determined by graphical intrapolation (MIC values (mg/L) are : 1 and 0.125 (ciprofloxacin), 0.5 and 0.03

492 (moxifloxacin), and 0.5 and 0.008 (gemifloxacin) for L. monocytogenes and S. aureus respectively.

493

494 Statistical analysis:

495 The raw data obtained for each individual antibiotic, and the corresponding Hill functions were compared using one way ANOVA (parametric) 496 and Kuskal-Wallis (non-parametric) tests found to be not significantly different (L. monocytogenes: $p=0.420$ and 0.152 , respectively: $S$. aureus: $p=0.351$ and 0.249 , respectively). The analysis was then repeated for comparison of antibiotic pairs (ciprofloxacin vs. gemifloxacin; ciprofloxacin vs. moxifloxacin; moxifloxacin vs. gemifloxacin) using unpaired t-test and showed no significant difference for any comparison

$499 \quad(p>0.18)$.

500 

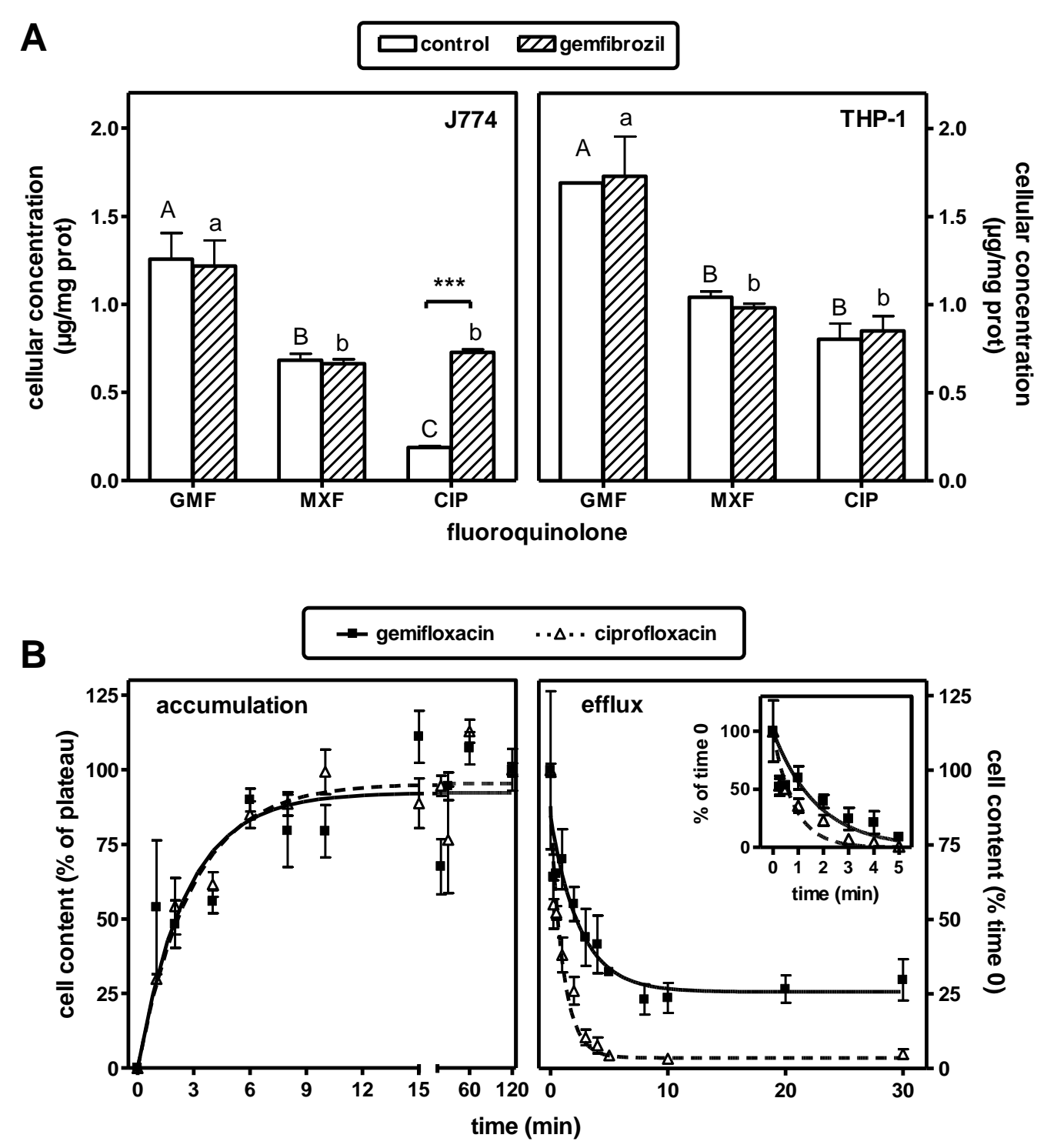

505 Caption to Figure 1: Accumulation and efflux of fluoroquinolones.

506 A (upper panel): accumulation of gemifloxacin (GMF), moxifloxacin (MXF), and

507 ciprofloxacin (CIP) in wild-type $\mathrm{J774}$ mouse macrophages (left) and THP-1 human

508 monocytes (right) incubated during $2 \mathrm{~h}$ with $20 \mathrm{mg} / \mathrm{L}$ in control conditions (open bars) 509 or in the presence of the Mrp inhibitor gemfibrozil $(500 \mu \mathrm{M}$; hatched bars). All values

510 are the means of 3 independent determinations \pm SD. Statistical analysis (ANOVA):

511 control vs. gemfibrozil, ${ }^{* * *} p<0.001$; comparison of fluoroquinolones: bars with

512 different letters are different from one another $(p<0.001$; caps letters, control

513 conditions; small letters, + gemfibrozil). 
514 B (lower panel): kinetics of accumulation (left) and efflux (right) of gemifloxacin

515 compared to ciprofloxacin in $\mathbf{J 7 7 4}$ macrophages (see [10] for efflux of moxifloxacin) .

516 For accumulation studies, cells were transferred to medium containing a fixed

517 amount of drug $(20 \mathrm{mg} / \mathrm{L})$ and collected at the times indicated in the abscissa. For

518 efflux, cells were first exposed to the drug for $2 \mathrm{~h}$ at a concentration of $20 \mathrm{mg} / \mathrm{L}$,

519 gently washed, transferred to drug free medium and collected at the times indicated

520 in the abscissa. Data were used to fit a one phase exponential association function

521 for influx [ $y=y_{\max _{a}} x\left(1-e^{-k_{\text {in }} x t}\right)$ ] and a one phase exponential decay function

522 for efflux $\left[y=y_{\max _{x}} x e^{-k_{\text {out }} x t}+\right.$ plateau) $]$ by nonlinear regression. Regression

523 parameters for influx: (a) gemifloxacin, $\mathrm{R}^{2}=0.780, k_{\text {in }}=0.386 \pm 0.123 \mathrm{~min}^{-1}$; (b)

524 ciprofloxacin, $\mathrm{R}^{2}=0.922, k_{\text {in }}=0.348 \pm 0.066 \mathrm{~min}^{-1}$. Regression parameters for efflux:

525 (1) main graph, (a) gemifloxacin, $\mathrm{R}^{2}=0.897, k_{\text {out }}=0.403 \pm 0.122 \mathrm{~min}^{-1}$, plateau $=$

$52625.71 \pm 4.63$; (b) ciprofloxacin, $\mathrm{R}^{2}=0.949, k_{\text {out }}=0.949 \pm 0.204 \mathrm{~min}^{-1}$, plateau $=$

$5273.56 \pm 3.24)$; (2) Inset: data for the initial stage of efflux $(0-5 \mathrm{~min})$ and corrected for

528 differences in plateau reached after $10 \mathrm{~min}$, (a) gemifloxacin, $R^{2}=0.658$,

$529 k_{\text {out }}=0.571 \pm 0.138 \mathrm{~min}^{-1}$; (b) ciprofloxacin, $\mathrm{R}^{2}=0.909, k_{\text {out }}=1.216 \pm 0.209 \mathrm{~min}^{-1}$.

530 Statistical analysis (paired $t$ - test two-tailed): Influx, no significant difference in rate

531 constants; absolute values of plateaus of accumulation were different and in line with

532 data of Figure 1). Efflux: Main graph, comparison of all values: $p<0.001$ ), plateaus

533 values only: $p<0.001, k$ values only: $p<0.001$; Inset: comparison for all values:

$534 p=0.016, k_{\text {out }}$ values only: $p<0.001$. 
A

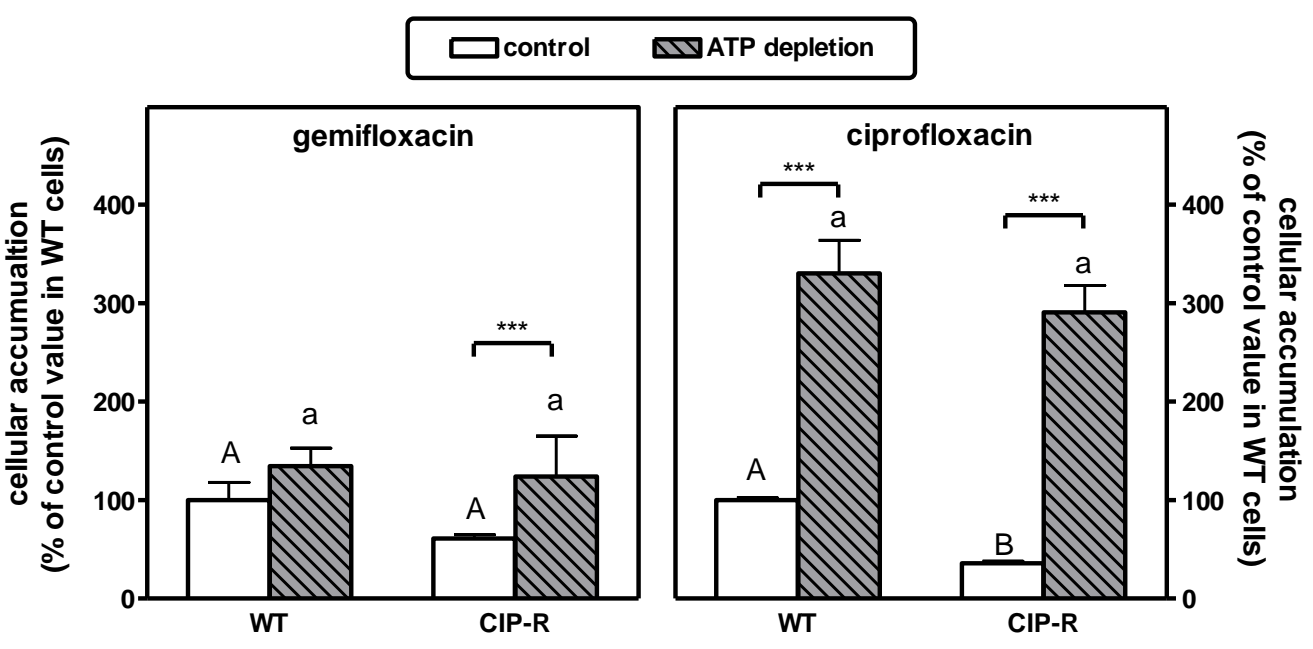

B

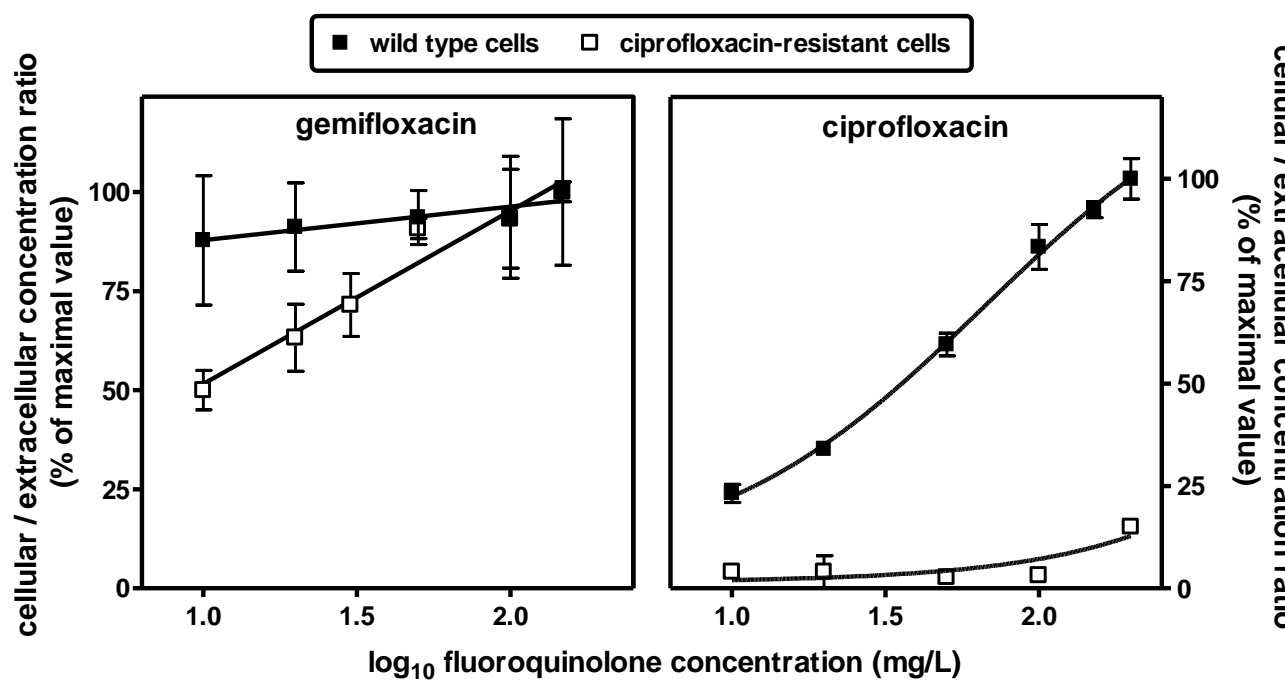

538 Caption to Figure 2: Cellular accumulation of gemifloxacin as compared to

539 ciprofloxacin in wild-type or ciprofloxacin-resistant J774 mouse macrophages (see

540 [11] for the corresponding data with moxifloxacin) A (upper panel): cells were

541 incubated for $2 \mathrm{~h}$ in control conditions (open bars) or in ATP-depleted cells (gray

542 hatched bars) with a fixed concentration ( $20 \mathrm{mg} / \mathrm{L}$ ) of gemifloxacin (left) or

543 ciprofloxacin (right) with wild-type cells (WT) or ciprofloxacin-resistant cells (CIP-R).

544 Data are expressed in percentage of the value measured in wild-type cells in control

545 conditions for each fluoroquinolone. All values are the means of 3 independent

546 determinations \pm SD. Statistical analysis (ANOVA): control vs. ATP-depletion, ${ }^{* * *} \mathrm{p}$

$547<0.001$; WT vs. CIP-R cells: bars with different letters are different from one another

548 ( $p<0.05$; upper case letters, control conditions; lower case letters, ATP-depletion).

549 B (lower panel): Influence of the extracellular concentration of gemifloxacin (left) and

550 ciprofloxacin (right) on their cellular to extracellular concentration ratio in wild-type 
551 (closed symbols) or ciprofloxacin-resistant (open symbols) $\mathrm{J} 774$ mouse

552 macrophages, measured after $2 \mathrm{~h}$ of incubation. The cellular concentration was

553 expressed as $\mu \mathrm{g}$ per mg protein. Data are expressed in percentage of the highest

554 value observed in wild-type cells for each fluoroquinolone. All values are the means

555 of 3 independent determinations \pm SD.

556

557 

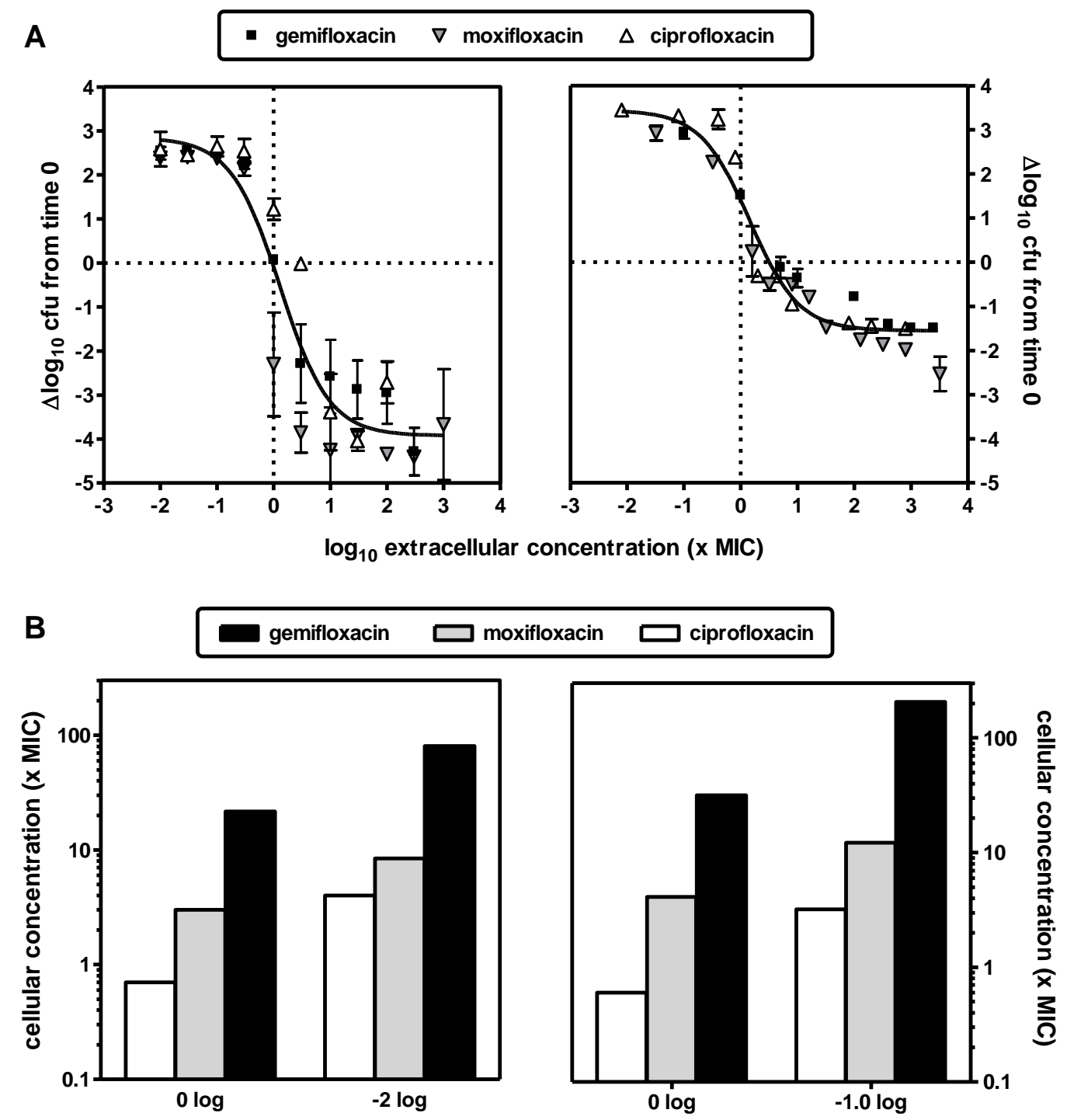

target effect ( $\Delta$ cfu at $24 \mathrm{~h}$ compared to initial inoculum)

561 Caption to Figure 3: Concentration-response of the activities of gemifloxacin,

562 moxifloxacin, and ciprofloxacin against phagocytized L. monocytogenes EGD (left)

563 and S. aureus ATCC25923 (right) in wild-type J774 macrophages.

564 A (top): after phagocytosis and elimination of the extracellular bacteria, cells were

565 incubated for $24 \mathrm{~h}$ with increasing concentrations of antibiotic (total drug) covering a

$566 \sim 0.01$ to $\sim 1,000 \times$ MIC range (MIC [mg/L] were 1 and 0.125 [ciprofloxacin], 0.5 and

5670.03 [moxifloxacin], and 0.5 and 0.008 [gemifloxacin] for L. monocytogenes and

568 S. aureus respectively). The graphs show the change in the number of cfu (log

569 scale) per mg of cell protein compared to the initial post-phagocytosis inoculum 
570 (ordinate) as a function of the extracellular concentration of each drug expressed in

571 multiple of its MIC (abscissa). In each graph, the horizontal dotted line corresponds

572 to an apparent static effect and the vertical line to the MIC of the drug. A single

573 sigmoidal regression has been fit to all data sets (see Figure SP2 for individual

574 regression curves. The pertinent regression parameters and numerical values of the

5754 key pharmacological descriptors $\left(E_{\min }, E_{\max } ; E_{50}, C_{s}\right)$ are shown Table 1 for each

576 drug - bacteria combination.

577 B (bottom): the ordinates show the calculated cellular concentrations (total drug; in

578 multiples of MIC) needed to achieve two predefined activity levels (targets) shown on

579 the abscissa (static effect [no apparent change in cfu]; 2 (L. monocytogenes) or 1

580 (S. aureus) $\log _{10}$ cfu decrease compared to the initial, post-phagocytosis inoculum).

581 The cellular concentrations were calculated by (i) using the concentration-response

582 curves shown in $\mathbf{A}$ to determine the extracellular concentrations needed to achieve

583 the target effects (graphical intrapolation), and (ii) using the data of Figure 2B (wild

584 type cells) to calculate the corresponding apparent total cellular concentrations of

585 gemifloxacin and ciprofloxacin (for moxifloxacin, we used the accumulation data

586 published in [10]) based on a conversion factor of $3.08 \mu \mathrm{L}$ of total cell volume per $\mathrm{mg}$

587 protein as determined experimentally for wild type $\mathrm{J774}$ macrophages in previous

588 studies [9].

589 


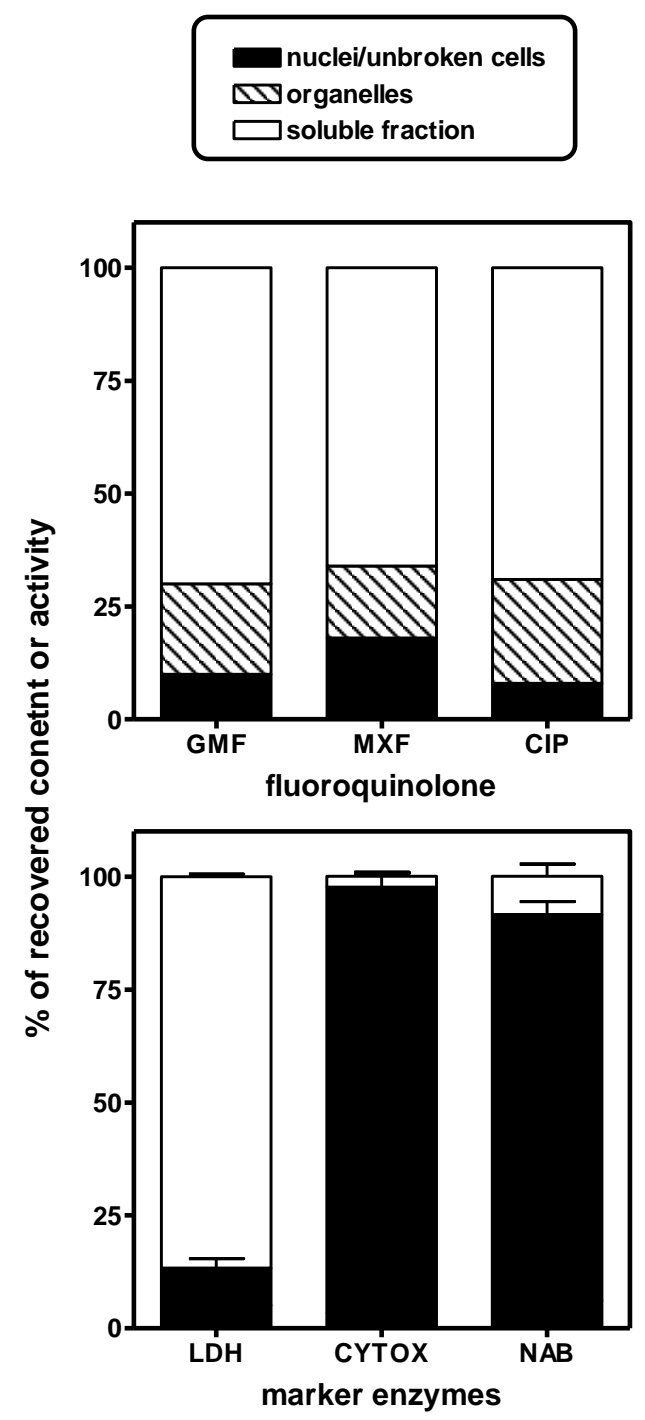

592

Caption fo Figure 4: Subcellular distribution of gemifloxacin (GMF), moxifloxacin (MXF), and ciprofloxacin (CIP) in J774 mouse macrophages incubated for $2 \mathrm{~h}$ with $50 \mathrm{mg} / \mathrm{L}$ of each drug. The upper panel shows the antibiotic content in the nuclear/unbroken cells, organelles, and soluble fractions expressed in percentage of the total recovered amount (each bar corresponds to a separate experiment). The lower panel shows the distribution of lactate dehydrogenase (LDH; marker of the cytosol), cytochrome-c-oxydase (CYTOX; marker of mitochondria), and N-acetyl- $\beta$ hexosaminidase (NAB; marker of lysosomes) as the mean values $( \pm S D)$ of the 3 experiments (corresponding to each of the individual experiment shown in the upper panel). 


\section{Vallet et al. Intracellular activity of fluoroquinolones - Supplementary Material Figure SP1}

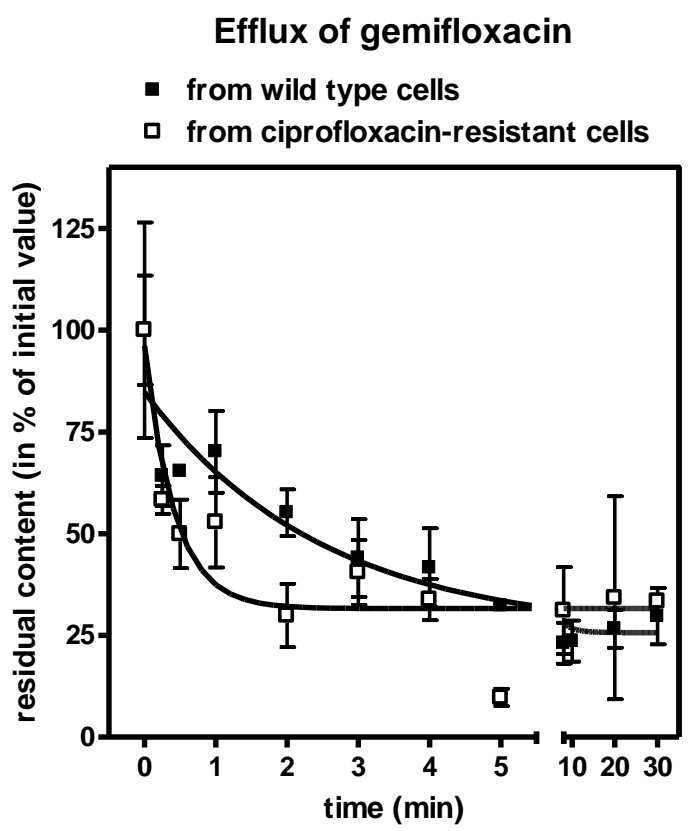

608

609 Caption to Figure SP1: Kinetics of efflux of gemifloxacin from wild-type and

610 ciprofloxacin-resistant $\mathbf{J} 774$ cells. Cells were exposed to gemifloxacin $(20 \mathrm{mg} / \mathrm{L})$ for

$6112 \mathrm{~h}$ and then transferred to antibiotic-free medium for up to $30 \mathrm{~min}$. Regression

612 parameters: (a) wild-type cells (same data as in Figure 2), $R^{2}=0.896$,

$613 k_{\text {out }}=0.403 \pm 0.122 \mathrm{~min}^{-1}$, plateau $=25.71 \pm 4.63$; (b) ciprofloxacin-resistant cells,

$614 \mathrm{R}^{2}=0.830, k_{\text {out }}=2.39 \pm 0.907 \mathrm{~min}^{-1}$, plateau $=31.6 \pm 4.0$ ). 


\section{Figure SP2}

A Staphysococcus aureus ATCC 25923
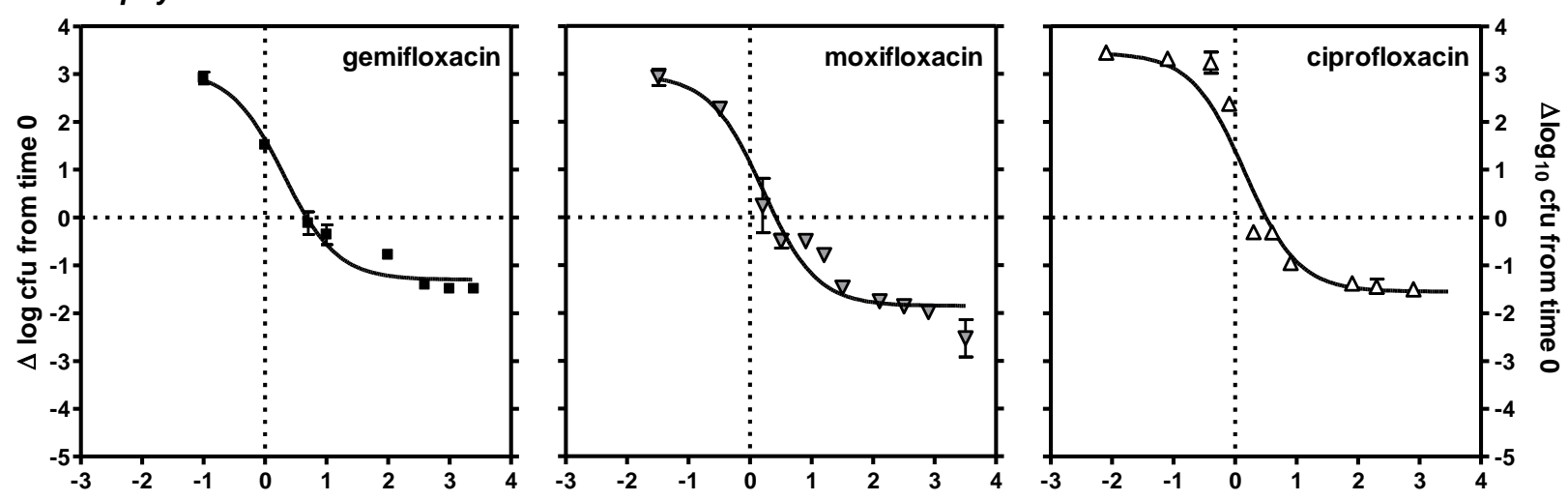

B
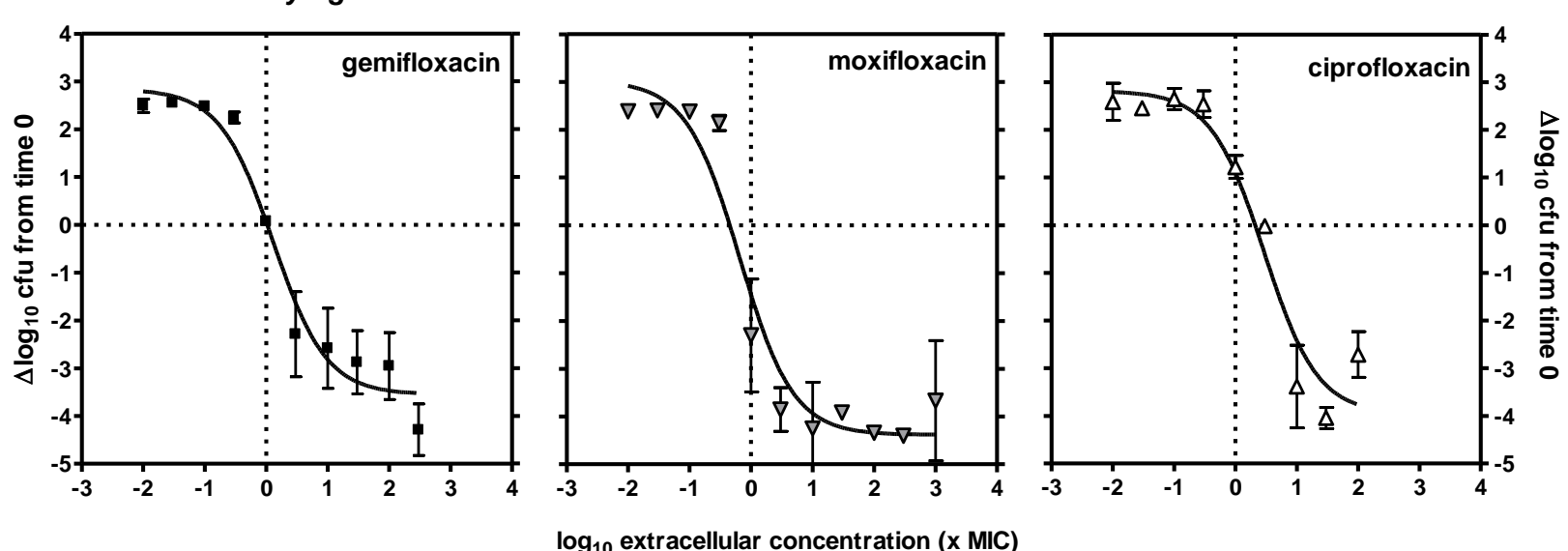

619 Caption to Figure SP2: Concentration-response of the activities of gemifloxacin,

620 moxifloxacin, and ciprofloxacin (CIP) against S. aureus ATCC25923 (top) and

621 L. monocytogenes EGD (bottom) in wild-type J774 macrophages. Cells were

622 incubated with increasing concentrations of antibiotic (total drug) for $24 \mathrm{~h}$. Each

623 graph shows the change in the number of cfu (log scale) per mg of cell protein

624 compared to the initial post-phagocytosis inoculum (ordinate) as a function of the

625 extracellular concentration of each drug expressed in multiples of its MIC (abscissa).

626 In each graph, the horizontal dotted line corresponds to an apparent static effect and

627 the vertical line to the MIC of the drug. A sigmoidal regression has been fitted to

628 each set of data (see Table 1 for the pertinent regression parameters and numerical

629 values of the four key pharmacological descriptors $\left(E_{\min }, E_{\max } ; E_{50}, C_{s}\right)$. 


\section{Table SP1: Physico-chemical properties of fluoroquinolones and azithromycin at physiologically-relevant pHs}

633 The data indicate that (i) ciprofloxacin, moxifloxacin, and gemifloxacin display quite similar biophysical properties although showing distinct cellular 634 accumulation levels (gemifloxacin > moxifloxacin > ciprofloxacin; see Results) that are not correlated to the minor differences seen; (ii) these 635 properties are very different from those of azithromycin, a drug known to accumulate extensively in lysosomes by proton-trapping (see 636 Discussion). The pHs considered are those of the extracellular (7-7.4) and of the lysosomal (5-5.4) milieus, respectively.

637

\begin{tabular}{|c|c|c|c|c|c|c|c|c|c|c|c|c|}
\hline \multirow{3}{*}{ Drug } & \multirow{3}{*}{$\begin{array}{c}\mathrm{pKa}_{1}{ }^{\mathrm{a}} \\
\text { (acidic) }\end{array}$} & \multirow{3}{*}{$\begin{array}{c}\mathrm{pKa}_{2}^{\mathrm{a}} \\
\text { (basic) }\end{array}$} & \multicolumn{6}{|c|}{ species in solution (calculated \%) ${ }^{a}$} & \multicolumn{2}{|c|}{$\log P^{b}$} & \multicolumn{2}{|c|}{ calculated $\log D^{a}}$, \\
\hline & & & \multicolumn{3}{|c|}{ pH 7.4} & \multicolumn{3}{|c|}{ pH 5.4} & \multirow{2}{*}{ calculated $^{\mathrm{a}, \mathrm{d}}$} & \multirow{2}{*}{ experimental $^{\mathrm{e}}$} & \multirow{2}{*}{ pH 7} & \multirow{2}{*}{ pH 5} \\
\hline & & & cationic & zwitterionic & anionic & cationic & zwitterionic & anionic & & & & \\
\hline ciprofloxacin & 5.8 & 8.7 & 2 & 93 & 5 & 69 & 30 & 0 & 1.63' & 2.30 & -1.38 & -1.62 \\
\hline moxifloxacin & 5.6 & 9.4 & 2 & 97 & 1 & 66 & 34 & 0 & 1.90 & 2.90 & -1.72 & -1.33 \\
\hline gemifloxacin & 5.5 & 9.5 & 1 & 98 & 1 & 47 & 52 & 0 & 1.04 & 2.30 & -2.54 & -1.78 \\
\hline azithromycin & - & $\begin{array}{l}8.9^{f} \\
9.6\end{array}$ & $96.98^{g}$ & 0.02 & 0 & $99.97^{\mathrm{g}}$ & 0 & 0 & 2.44 & 4.02 & -1.99 & -4.41 \\
\hline
\end{tabular}

$639{ }^{a}$ calculated using Reaxys (http://www.reaxys.com) with the ChemAxon's Marvin plug-in calculators (http://www.chemaxon.com/marvin). The 640 actual values of the $\mathrm{pK}_{\mathrm{a}}$ of the acidic function may be about 0.5 units higher due to the influence of the vicinal carbonyl function [1].

$641{ }^{b} \log \mathrm{P}$ : partition coefficient (log of the ratio of the concentrations of the unionized compound between a non polar [octanol] and a polar [water] 642 phases); 
${ }^{\mathrm{c}} \log \mathrm{D}$ : distribution coefficient (log of the ratio of the sum of the concentrations of all forms of the compound [ionized plus un-ionized] in each of thee two phases at a given $\mathrm{pH}$ )

d These values are the arithmetic average of three methods of calculations (Viswanadhan's fragmentation; Klopman's fragmentation; and PHYSPROP@ database [see https://www.reaxys.com/static/marvin/marvin 537 /help/calculations/partitioning.html for details]).

e value as reported in Drugbank (see http://www.drugbank.ca and [2]

f azithromycin is a dicationic drug

${ }^{\mathrm{g}}$ dicationic form (monocationic form: $3 \%$ at $\mathrm{pH} 7.4$ and $0.03 \%$ at $\mathrm{pH} 5.4$; a zwitterionic form is virtually inexistent $(<0.001 \%$ ) at these $\mathrm{pH}$ values).

\section{References}

[1] Nikaido H, Thanassi DG. Penetration of lipophilic agents with multiple protonation sites into bacterial cells: tetracyclines and fluoroquinolones as examples. Antimicrob Agents Chemother. 1993 Jul;37(7):1393-9. [PMID: 8363364]

[2] Wishart DS, Knox C, Guo AC, Shrivastava S, Hassanali M, Stothard P, Chang Z, Woolsey J: DrugBank, a comprehensive resource for in silico drug discovery and exploration, Nucleic Acids Res. 2006 Jan 1;34 (Database issue): D668-72 [PMID: 16381955] 